\title{
RESEÑA
}

\section{DEMOCRATIZACIÓN Y REGULACIÓN DEL DERECHO DE ACCESO A LA INFORMACIÓN EN MÉXICO}

Título: Democratización y regulación del derecho de acceso a la información en México.

Autor: Fidela Navarro Rodríguez.

Edición: Fundación Universitaria de Derecho, Administración y Política, S.C.

No. de páginas: $165 \mathrm{p}$.

Año: 2004.

En un Estado democrático la legitimidad del Derecho se sustenta en las condiciones del proceso de creación de los instrumentos jurídicos que sustentan el Estado de Derecho. Por lo que la documentación de los hechos que en este campo han estado sucediendo en México en los últimos años, en materia de derecho a la información, nos obligan a un alto en el camino para la reflexión y balance que aporte elementos de diagnóstico y emprender nuevas formas de acción en el campo de las políticas públicas.

El momento actual no puede ser más oportuno, en los últimos años se ha abierto un debate serio y de altura, sobre el papel que desarrollan los medios de comunicación en nuestro país, y fundamentalmente, sobre la necesidad de actualizar nuestro marco jurídico en materia de libertades de expresión e información y de derecho a la información.

En toda democracia consolidada, como se señala en la obra objeto de estos comentarios, los ciudadanos tienen derecho a la diversidad de fuentes de información independientes y de carácter gubernamental, que les permitan evaluar acciones, establecer opiniones y participar en el espacio público y político. El derecho al acceso a la información pública se localiza en el ámbito del derecho a la información, entendido como la garantía que toda persona tiene para obtener información, informar y ser informada, y engloba, tanto libertades individuales (libertades de pensamiento, expresión e imprenta) como otras de carácter social (el derecho a recibir información objetiva, oportuna y el acceso a la documentación pública). 
El análisis y conocimiento crítico de los proyectos legislativos que en materia de derecho a la información se han desarrollado en nuestro país contribuirán a la reflexión académica y política que permita no sólo dar cuenta de sus características y consecuencias, sino para construir una propuesta que nos permita avanzar en el ejercicio de la política, y en la definición de acciones en la materia.

Las condiciones para la Reforma se dieron en México cuando nos encontramos en un proceso de transición a la democracia a partir del año 2000, cuando las reformas necesarias debieron ser asumidas, para pasar de la mera alternancia a la verdadera transición.

Contrariamente a los logros en el campo del derecho de acceso a la información con la Ley Federal de Transparencia y Acceso a la Información Publica Gubernamental (24 de Abril de 2002), en temas como la garantía a la libertad de expresión y el derecho a la información, el régimen de la radio y la televisión y la regulación actualizada de las Telecomunicaciones los resultados han sido pocos.

Las barreras construidas por una basta zona de impunidad en la que los actores dominantes del proceso de la comunicación han generado inercias de inamovilidad que nos tienen aún con una Ley de Imprenta -reguladora de la libertad de expresión- de 1917, una Ley de Radio y Televisión de 1960 y una de Telecomunicaciones de 1995 que aunque más joven, anciana ya por la vertiginosa dinámica del desarrollo tecnológico que regula.

Desde la Declaración del Hombre de 1789, en su Artículo 17 encontramos antecedentes del concepto básico de la naturaleza de la comunicación social y la información:

Ningún hombre podrá ser perseguido por razón de sus escritos, que haya hecho imprimir o publicar sobre cualquier materia si no provoca la desobediencia de la ley, el derrocamiento de los poderes constituidos, la resistencia a sus disposiciones cualquiera de los actos declarados crímenes por la ley.

La Convención Americana Sobre Derechos Humanos de la OEA de 1969, en San José de Costa Rica conocido como Pacto de San José define de manera clara los conceptos 
que refieren a la libertad de expresión, derecho a la privacidad, derecho a la información y derecho de réplica.

Si el ejercicio de los derechos y libertades aquí mencionados no estuviera ya garantizado por disposiciones legislativas o de otro carácter, los Estados partes se comprometen a adoptar, con arreglo a sus procedimientos constitucionales y a las disposiciones de esta Convención, las medidas legislativas o de otro carácter que fueren necesarias para hacer efectivos tales derechos y libertades.

La libertad de expresión y el derecho a la información se encuentran fundamentados en el artículo 6o. de la Constitución, éste último en virtud de la adición de 1977:

“el derecho a la información será garantizada por el estado”.

No obstante lo atinado del término, este derecho no ha podido ser garantizado y las disposiciones que a la fecha están vigentes se encuentran contenidas en ordenamientos obsoletos, tanto por lo añejo de su promulgación como por su inaplicabilidad.

En una Reforma del Estado no se puede permitir que el derecho a la información y a la libertad de expresión sigan bajo la "amenaza" de una ley promulgada por Venustiano Carranza el 12 de abril de 1917, como reglamentaria de los Artículos 6 y 7 Constitucionales, que en su misma introducción apunta su carácter transitorio cuando se proclama "“en tanto el Congreso de la Unión (los) reglamente”, no hay razón alguna para continuar con la ley del "en tanto".

El Estado no se ha preocupado de reglamentar tan importante derecho social, cuya naturaleza deviene de su facultad de tutelar las necesidades sociales para que garanticen la satisfacción de una situación de carácter general: Que la sociedad se mantenga informada, con todas las implicaciones del concepto.

Para hacer efectivo este derecho, es indispensable que el Estado se manifieste a través de sus órganos constituidos, los que en sus respectivos ámbitos de competencia están facultados para regular aspectos que tengan implicaciones en la sociedad, como es el caso del aquí revisado derecho a la información. 
En la primera parte de la obra la autora explica que es el derecho a la información y cuál es la importancia y significado del derecho de acceso a la información pública como figura jurídica y como se relacionan estos con los diferentes actores sociales y políticos, tanto en la teoría como en la práctica, a partir del ejemplo del grupo Oaxaca (conformado en el año 2001 por un conjunto de académicos, periodistas, asociaciones no gubernamentales, juristas y actores mediáticos, sin dirección unipersonal con el propósito de crear nuevos escenarios y actores en el marco de la regulación del derecho a la información).

En la segunda parte se analizan la gestión y las posibilidades del derecho a la información y de que forma pudo haber influido en el impulso de un ley pública en México en relación a Estados Unidos, Europa y Latinoamérica y como podría hacerlo en otros países vecinos, principalmente de Latinoamérica como ejemplo de acción comunicativa y necesidad jurídica. Incluyendo un balance de los intentos históricos e infructuosos en México por regular el articulo 6to constitucional hasta llegar al momento en que surge el citado Grupo Oaxaca.

Posteriormente en la tercera parte se analizan los intereses del ejecutivo para seguir el proceso iniciado por los diferentes actores, es decir, qué suponía para el gobierno aprobar una ley, si era o no un tema de agenda, cómo y quienes trabajaron las iniciativas y su gestión política y mediática. Así mismo cómo los partidos políticos estaban abordando el tema de las iniciativas, quienes eran sus representantes y de que manera se pretendía impulsar una ley reguladora de una garantía tan importante como el derecho a la información.

Por último se explica como fue desarbolándose una acción comunicativa concreta para la elaboración de las tres iniciativas de ley presentadas finalmente por el ejecutivo, el PRD y el grupo Oaxaca.

En un ámbito inédito en donde el sujeto obligado es el mismo poder publico se logró en 2002 y con plena vigencia desde junio de 2003, la promulgación de la Ley Federal de Transparencia y Acceso a la Información Publica Gubernamental, marcado un cambio fundamental en la relación entre gobierno y gobernados, en los que la información adquiere su valor como instrumento de rendición de cuentas y que, en su ejercicio, 
deberá marcar la diferencia en las decisiones informadas que los ciudadanos tomemos a la hora de elegir los rumbos.

La Ley Federal de Transparencia y Acceso a la Información Pública, ha sido ejemplo en cuanto al proceso legislativo que le da origen, especialmente cuando se trata de temas de relevancia y consenso social para el Estado de Derecho, pues en menos de seis meses se revisaron en el Congreso tres iniciativas de ley para lograr un solo proyecto.

Sabemos que aun tenemos limitantes en este tema y que el derecho a la información tiene un futuro promisorio en el que la sociedad en su conjunto tenemos que hacer un frente común para que se nos respeten nuestros derechos fundamentales y que se sigan gestionando los apoyos necesarios para el desarrollo de estas investigaciones.

Isidoro Beltrán Verduzco. Maestro en Ciencias. Candidato a Doctor en Enseñanza Superior por el Centro de Investigación y Docencia en Humanidades del Estado de Morelos. Profesor Investigador. Universidad Autónoma Indígena de México y catedrático de la asignatura de Derecho de la Información en la Universidad de Occidente. 